\title{
ESTILOS PARENTAIS, ESTILOS ATRIBUCIONAIS E BEM-ESTAR PSICOLÓGICO EM JOVENS UNIVERSITÁRIOS ${ }^{+}$
}

\author{
PARENTAL STYLES, ATTRIBUTIONAL STYLES AND PSYCHOLOGICAL \\ WELLBEING IN YOUNG ADULTS ATTENDING UNIVERSITIES
}

Mariana Gonçalves Boeckel* Jorge Castellá Sarriera**

Boeckel MG, Sarriera JC. Estilos parentais, estilos atribucionais e bem-estar psicológico em jovens universitários. Rev Bras Crescimento Desenvolv Hum 2006; 16(3):53-65.

Resumo: Partindo da premissa de que a família possui tarefas essenciais para a formação e o desenvolvimento dos seus membros, o presente estudo buscou identificar as correlações existentes entre as estratégias educacionais, estilos atribucionais e bem-estar psicológico em adultos jovens universitários. Foram realizadas análises correlacionais e de regressão múltipla. Os resultados apontam que o estilo parental autorizante, de forma geral, tem desdobramentos que se expressam em elevados níveis de bem-estar. Quanto ao estilo parental autoritário, notou-se que à maior intensidade do autoritarismo no estilo, há correspondência de maiores níveis de estabilidade na atribuição causal. Concernente aos estilos atribucionais, percebeu-se que as dimensões globalidade e estabilidade corresponderam a piores níveis de bem-estar psicológico. Esses achados salientam a importância dos efeitos dos estilos parentais e estilos atribucionais no bem-estar psicológico para futuras ações psico-educativas.

Palavras-chave: Estilos parentais. Estilos atribucionais. Bem-estar psicológico. Adultos jovens.

\section{INTRODUÇÃO}

As relações que se estabelecem na família original com os cuidadores - sejam estes consangüíneos ou não -, assim como as relações que se formam com outros sistemas mais próximos (escola, parentes, amigos), são componentes fundamentais no modo como o indivíduo graduará a lente com que vislumbra o seu mundo. A família, sob esse aspecto, é um laboratório de vivências relacionais e de aprendizagens.

As práticas educacionais exercidas em diferentes configurações familiares e as repercussões destas no comportamento dos filhos se tornaram de grande interesse para diversos estudiosos ${ }^{1-9}$.

Baumrind ${ }^{1}$, uma das pioneiras nos estudos sobre as estratégias educativas intrafamiliares, salienta a importância da intensidade do controle parental, juntamente com o apoio e afeto na execução das estratégias para o desenvolvimento humano. A autora ressalta que o controle, o apoio e o afeto permeiam as atitudes dos pais para com os filhos. A partir disso, formulou a diferenciação de três tipos de estilos parentais: estilo autoritário, estilo permissivo e estilo autorizante ${ }^{+}$. No presente estudo serão utilizados os conceitos de Baumrind ${ }^{1-3}$ no que se refere à tipologia de estilos parentais.

Este artigo integra a dissertação de mestrado: Estilos Parentais, Estilos Atribucionais e Bem-Estar Psicológico em Adultos Jovens. Mariana Boeckel. Apoio da agência financiadora CAPES.

** Mariana Gonçalves Boeckel é psicóloga, Mestre em Psicologia Social e da Personalidade do Programa de PósGraduação em Psicologia da PUCRS. Endereço para correspondência: Av. Taquara 277/302 - Petrópolis - Porto Alegre. E-mail: mariana_boeckel@yahoo.com.br

**** Jorge Castellá Sarriera é psicólogo e psicopedagogo. Mestre em Psicologia Escolar. Doutor em Psicologia. 
Os pais autoritários crêem em estratégias alicerçadas na obediência, em punições, no uso de medidas de força, sempre manifestadas através da imposição. O controle faz-se presente em elevado nível; não há espaço para o diálogo ${ }^{1}$. Esse controle intenso limita o desenvolvimento da autonomia, já que não considera as necessidades da criança, tampouco as competências inerentes a cada idade desenvolvimental. Como conseqüência, há comportamentos submissos, dependentes, reações passivo-agressivas, baixas motivações para realizações ${ }^{1-3}$. Lamborn e cols. ${ }^{10}$ evidenciaram que adolescentes que percebem seus pais como autoritários tendem a se conformar aos padrões sociais adultos e a conservarem baixos níveis de auto-conceito. Nota-se um inadequado uso do poder; questão importante, já que o equilíbrio de poder, assim como a reciprocidade e o afeto, são características fundamentais para um adequado desenvolvimento humano no contexto familiar ${ }^{11}$.

Por sua vez, Cheng e Furnham ${ }^{5}$ identificaram o estilo parental materno autoritário como o único preditor direto de felicidade, resultado contrário aos diversos estudos sobre esse estilo ${ }^{4,12}$.

O estilo permissivo tem como ponto fundamental a idéia de que a criança possui a tendência natural à socialização. Os pais devem deixar a criança aprender a identificar suas necessidades pois assim ela poderá expressar sua capacidade para auto-atualização. $\mathrm{O}$ adulto permissivo parte de uma postura afirmativa, de aceitação, em que os pais vêem a si como um recurso para o filho utilizar somente quando desejar, mas não como um agente ativo e responsável. Pais permissivos evitam o controle, mas, com freqüência, ficam descontentes por não terem o controle da criança ${ }^{1-2}$.

Por fim, o estilo autorizante salienta a idéia de que o cuidador não precisa decidir entre uma disciplina autoritária ou permissiva, podendo alternar suas atitudes partindo das contribuições das duas disciplinas. Os pais autorizantes encorajam as verbalizações, dividem com os filhos as razões por trás do policiamento parental, dão espaço para argumentações quando há recusa à obediência. As atitudes autônomas e disciplinadas são valorizadas. Ao mesmo tempo, há o exercício de um controle firme quando a criança desobedece, mas não punem a criança por intermédio de privações rígidas. Há sinergia entre o controle e o afeto ${ }^{2}$. Esse estilo influencia significativamente a construção das habilidades dos filhos para enfrentar situações estressantes, assim como há evidências de maiores níveis de competência psicossocial, menores índices de comportamentos disfuncionais $^{7}$ e melhores níveis de auto-estima ${ }^{12}$. $\mathrm{O}$ equilíbrio de poder, a reciprocidade e o afeto salientados por Bronfenbrenner ${ }^{11}$ estão presentes adequadamente nesta prática parental.

O bem-estar psicológico, de acordo com Petito e Cummins ${ }^{13}$, consiste em dois componentes: o primeiro é satisfação com a vida, a qual envolve uma avaliação cognitiva; e o segundo é afetivo, envolvendo sentimentos e humor. Petito e Cummins apontam fatores significantes no entendimento da qualidade de vida de jovens: suporte social e percepção do estilo parental de seus pais. Eles salientam que o suporte social aumenta o bem-estar, já que incita diversas influências positivas, as quais incluem a nutrição do senso de sentido de vida, assim como a promoção da saúde. Com alusão à importância do apoio da família no desenvolvimento da pessoa, Sarriera ${ }^{14}$, em uma pesquisa com jovens espanhóis, identificou que o suporte familiar é um importante fator na construção do bem-estar psicológico. Ao contrário, uma falta de suporte social foi relacionada a níveis inferiores de bemestar e até mesmo com psicopatologia.

A percepção do estilo parental também deve levar em consideração a fase de desenvolvimento da pessoa - uma percepção adolescente é, sem dúvida, diferente da de um adulto jovem. Na adultez jovem, surge a necessidade do resgate de um olhar mais contextualizado da realidade familiar. A saída da adolescência possibilita que os aspectos tumultuados e confusos vivenciados até então estejam mais claros. Há um importante retorno aos pais e familiares com o intuito de reconstrução de suas imagens, as quais estavam bastante mescladas com sentimentos intensos adolescentes ${ }^{15}$.

\footnotetext{
+ Será utilizado a palavra "autorizante" para a tradução do inglês de autoritative. Poderia ser, também, utilizado "com autoridade e afeto".
} 
Assim, as vivências na família de origem e nos contextos mais próximos, ocorridas no transcurso do desenvolvimento infantil e adolescente, bem como as percepções que se tem sobre elas, irão exercer forte influência na forma como as pessoas enfrentam situações cotidianas. Dentre os processos psicológicos envolvidos no enfrentamento de situações diárias, destacam-se as atribuições de causalidade.

Diante de diversas circunstâncias habituais, o ser humano realiza atribuições de causalidade para os eventos ocorridos rotineiramente. Sempre que a pessoa recorre às explicações que visam justificar os acontecimentos, está utilizando o conceito denominado "atribuição causal". Estas atribuições, por sua vez, são construídas ao longo do desenvolvimento humano. Morales ${ }^{16}$ salienta que o processo de atribuição de causalidade não é um processo puramente cognitivo, dado que há importantes implicações sociais, as quais se referem tanto às funções que desempenham quanto à forma em que são moduladas pelo entorno social e cultural.

Heider e Jones e Davis, citados por Morales $^{16}$, juntamente com Kelley ${ }^{17}$ e Weiner ${ }^{18-19}$ desenvolveram diversos estudos acerca das atribuições causais. Heider buscou entender como se atribui as "causas" aos sucessos ocorridos, especialmente os sucessos inesperados. O processo de atribuição, para este autor, cumpre funções de predição e controle do comportamento. Nele se procura encontrar uma explicação para um determinado sucesso, o que traz tranqüilidade. Para Weiner, as atribuições direcionam os sentimentos; e, por sua vez, as reações emocionais irão direcionar os comportamentos.

Peterson e Seligman ${ }^{20}$ partiram do pressuposto que as pessoas tinham um padrão geral de atribuição de causalidade e, então, estudaram a formação de um estilo de atribuição. Para eles, o entendimento acerca dos estilos atribucionais origina-se no estudo do fenômeno da desesperança aprendida. Seligman ${ }^{22-23}$ pressupôs que o desamparo aprendido poderia estar relacionado com as diferenças das atribuições causais, as quais as pessoas formulavam frente a situações estressantes e incontroláveis decorridas em suas vidas ${ }^{22-23}$. Alguns anos mais tarde, Peterson e Seligman ${ }^{20}$ definiram o estilo atribucional como uma variável da personalidade.

Abramson, Seligman, e Teasdale ${ }^{23}$ formularam três dimensões existentes no estilo atribucional: internalidade/ externalidade, estabilidade/ instabilidade e globalidade/ especificidade. Essas dimensões estão relacionadas às causas: internas (devido à própria pessoa) e externas (devido aos outros); estável (persiste ao longo do tempo) e instável (transitória); global (afeta diversos aspectos da vida) e específica (limitado ao evento em si).

Dentre os efeitos das dimensões, a internalidade excessiva pode influenciar negativamente a auto-estima quando há muita intensidade e, conseqüentemente, culpa e paralisação. Por outro lado, a internalidade pode permitir a sensação de locus de controle sobre a situação, visto que o "eu" é o ator principal, possibilitando mais autonomia e poder frente à situação. Por outro lado, a estabilidade afeta a cronicidade da desesperança e da depressão. Por fim, a globalidade influencia a percepção negativa dos eventos subseqüentes ${ }^{20}$.

Diversas pesquisas têm sido desenvolvidas com relação aos estilos atribucionais e suas implicações no sofrimento psíquico, em especial em quadros depressivos ${ }^{24-28}$. Haugen e Lund ${ }^{27}$ identificaram a auto-estima como um importante preditor na depressão, sendo que o estilo atribucional considerado interno, estável e global estaria relacionado a maiores níveis de depressão. Já externalidade, estabilidade e especificidade estariam associadas à saúde mental.

Rigby $^{29}$ menciona o estilo atribucional como mediador entre as características de personalidade e a qualidade de vida. E Chiara ${ }^{30}$ identificou os estilos atribucionais externos, instáveis e específicos como protetores para o desenvolvimento de sintomas e episódios depressivos.

Questões referentes a gênero e suas possíveis correlações com os estilos atribucionais têm sido investigadas significativamente ${ }^{31-34}$. Martinez e Sewell ${ }^{33}$ salientam a tendência das mulheres de atribuírem às situações negativas fatores causais internos, estáveis e globais com maior freqüência do que os homens.

Alguns estudiosos ${ }^{35}$ fazem referência à estabilidade dos estilos atribucionais ao longo do 
desenvolvimento humano. Outros acreditam que as atribuições para eventos negativos parecem ser mais estáveis do que as atribuições para os eventos positivos ${ }^{36-37}$. Já Schwartz, Kaslow, Seeley e Lewinsohn ${ }^{38}$ apontam instabilidade dos estilos no período da adolescência, tendo em vista as características inerentes desse período.

A pesquisa desenvolvida por Glasgow e cols. ${ }^{32}$ pontua a importante relação existente entre os estilos parentais e as atribuições causais em adolescentes. Esses autores salientam que a vivência de estilos parentais não autorizantes encontramse relacionada às atribuições causais disfuncionais. Ao mesmo tempo, Monestere ${ }^{34}$ refere que os jovens utilizam os modelos parentais para o desenvolvimento dos estilos atribucionais, ou seja, tendem a desenvolver estilos atribucionais similares aos de seus pais. Essa autora salienta a importante conexão da família no desenvolvimento das atribuições causais. Juntamente com isso, Peterson e Seligman ${ }^{20}$ sugerem que o desenvolvimento dos estilos atribucionais esteja relacionado às vivências na infância com os cuidadores (geralmente os pais), às críticas recebidas do meio (escola, professores) e às situações estressantes vivenciadas por cada um no transcurso do desenvolvimento.

As pesquisas apresentadas, apontando a importante influência das estratégias educacionais no comportamento e no bem-estar psicológico, assim como a possibilidade das atribuições causais serem construídas a partir de vivências familiares, motivaram a realização do presente estudo. Dessa forma, objetiva-se entender de que modo o estilo atribucional, o estilo parental e o bem-estar psicológico se correlacionam em um conjunto de adultos jovens universitários.

\section{MÉTODO}

\section{Participantes}

Foram participantes deste estudo 323 adultos jovens, de ambos os sexos, estudantes universitários de uma universidade particular de Porto Alegre, no Rio Grande do Sul (Brasil).

Utilizaram-se duas etapas de seleção de amostra. Primeiramente, selecionou-se uma amostra aleatória estratificada por setores de formação (filosófico-humanístico, sócio-jurídico-econômico, biomédico e técnico-científico). Na seguinte etapa, foi feita escolha por conveniência com relação aos cursos de graduação de cada setor. Os cursos que participaram desta investigação foram: Letras, Psicologia, Serviço Social, Relações Públicas, Direito, Medicina, Fisioterapia, Engenharias, Informática, Ciências Aeronáuticas e Arquitetura.

\section{Instrumentos}

Desenvolveu-se um questionário formulado a partir de instrumentos e escalas elaborados previamente, abordando variáveis no que se refere aos aspectos: biodemográficos, estilos atribucionais, bem-estar psicológico e estilos parentais.

\section{Questionário de Estilos Atribucionais - Expanded Attributional Style Questionnaire (EASQ)}

O EASQ busca identificar os estilos de atribuições de causa que utilizamos para os acontecimentos cotidianos. Há 24 questões hipotéticas sobre acontecimentos negativos em diversas áreas da vida do sujeito. Partindo de cada sentença são feitas três perguntas: a primeira faz referência à internalidade/externalidade; a segunda à estabilidade/instabilidade; e a terceira à globalidade/ especificidade. Abaixo de cada questão, há uma escala de sete itens que inicia no -3 e vai ao +3 , na qual os respondentes assinalam o número que melhor os descreve, partindo da idéia de um contínuo ${ }^{39}$.

A consistência interna obtida no estudo original foi de 0,66 para internalidade, 0,85 para estabilidade e 0,88 para globalidade ${ }^{39}$. Na presente investigação, obteve-se os seguintes Alphas de Crombach: 0,71 para internalidade, 0,86 para estabilidade e 0,88 para globalidade.

\section{Questionário Geral de Saúde de Goldberg (GHQ - 12)}

Essa escala foi desenvolvida por Goldberg ${ }^{40}$ para mensurar a percepção do bem-estar psicológico. Ela é realizada por meio da avaliação do grau de desvio no comportamento normal 
relacionado ao estado de saúde de uma pessoa partindo da comparação de seu estado atual com o usual. É composta por 12 questões, havendo quatro alternativas de respostas: duas de ausência, uma neutra e outra de presença de bem-estar psicológico.

A consistência interna obtida por Golberg ${ }^{40}$ foi de 0,83. Em 1996, esse instrumento foi validado na população de jovens porto-alegrenses e obteve um Alpha de Crombach de $0,80^{41}$. No presente estudo, foi obtido índice de 0,84 de consistência interna.

\section{Questionário de Estilos Parentais - Parental Authoritative Questionaire - PAQ}

O instrumento busca avaliar os conceitos de Baumrind referentes aos estilos parentais permissivo, autoritário e autorizante. É composto por 30 situações hipotéticas sobre as estratégias educacionais utilizadas pelos pais durante a infância de seus filhos. Há 10 situações que fazem referência ao estilo parental autoritário, $10 \mathrm{com}$ relação ao estilo autorizante e 10 ao estilo permissivo. Os filhos respondem em uma escala Likert de cinco pontos, sendo dois pontos referentes à discordância ("discordo totalmente" e "discordo"), um ponto neutro ("não concordo nem discordo") e dois que referentes à concordância ("concordo totalmente" e "concordo"). As respostas são fundamentadas na percepção dos filhos no que toca às estratégias educacionais que seus pais utilizaram com eles. Originalmente, foi aplicado um instrumento com relação à mãe e outro com relação ao pai, ambos com as mesmas questões $^{42}$. Nesta pesquisa, optou-se por utilizar somente um instrumento com relação aos pais como um todo.

A partir do teste de confiabilidade, Buri identificou os seguintes Alphas Crombach: relacionados aos estilos parentais das mães $-0,75$ para estilo permissivo, 0,85 para autoritário e 0,82 para autorizante; com relação aos estilos dos pais $-0,74$ para permissividade, 0,87 para autoritário e 0,85 para autorizante. Na presente pesquisa, obteve-se os seguintes Alphas de Crombach: 0,74 para permissivo, 0,85 para autoritário e 0,88 para autorizante.

\section{Tradução e adaptação dos instrumentos}

O processo de tradução dos instrumentos $P A Q$ e EASQ foi desenvolvido através de quatro juízes, os quais eram profissionais da área de Psicologia e tinham domínio da língua inglesa. Foi realizado back translation com o intuito de maior precisão na tradução. Foi obtido um coeficiente de concordância de Kappa de Cohen de 0,75.

Com relação à análise de conteúdo e de aparência, os questionários traduzidos foram aplicados em 10 adultos jovens universitários. Também foi realizado estudo piloto com 30 sujeitos a fim de avaliar a consistência interna (Alpha de Crombach), assim como a adequação dos instrumentos à proposta da investigação. O resultado da consistência interna do piloto para o Expanded Attibutional Style Questionnaire foi de 0,69 para internalidade, 0,85 para estabilidade e 0,78 para globalidade. Com relação ao Parental Authoritative Questionnaire foram obtidos os seguintes Alphas: 0,85 para permissivo, 0,88 para autoritário e 0,89 para autorizante. Por último, o questionário de saúde geral (GHQ-12) obteve Alpha de 0,84.

\section{Procedimentos de coleta dos dados $e$ considerações éticas}

Os alunos foram convidados a participar da pesquisa durante o período de aula. Após a informação sobre os objetivos do estudo, a apresentação por escrito do Termo de Consentimento Informado - o qual abarcava esclarecimentos sobre anonimato e sigilo - os participantes foram orientados quanto ao procedimento para preencher o questionário. A aplicação foi realizada na sala de aula, coletivamente e foi auto-administrada. Foi garantido o caráter voluntário da participação. A pesquisa teve aprovação do Comitê de Ética em Pesquisa da PUCRS sob número 027/04.

\section{RESULTADOS}

Os dados referentes às características biodemográficas dos participantes do estudo referiram-se, principalmente, às questões individuais, familiares e laborais. 
Do total dos participantes, $50,8 \%$ era do sexo feminino e $49,2 \%$ masculino. A idade oscilou de 18 a 35 anos, com média de 22,12 anos (desvio padrão $=3,761)$. A freqüência das idades entre 18 a 20 anos foi de $40,8 \%$; de 21 a 24 foi de $39,3 \%$; e de 25 a 35 , de $19,9 \%$. No que diz respeito ao estado civil, a grande maioria dos participantes estavam solteiros $(93,2 \%)$. Na questão que investigava relacionamentos afetivos, foi possível perceber que $55,7 \%$ tinham relacionamento estável. No que se refere à variável trabalho, $50,8 \%$ estava trabalhando. Entretanto, 20,7\% responderam que eram independentes financeiramente; e 79,3\% dos respondentes afirmaram que eram dependentes. No que diz respeito a com quem viviam, $62,2 \%$ referiram que moravam com os pais, $11,5 \%$ sozinhos, $9,3 \%$ com o companheiro e $17 \%$ com outros. Quanto à classe social, a maioria $(54,1 \%)$ considera-se classe média; enquanto $21,7 \%$ classe alta; $19,2 \%$ média baixa; e $1,6 \%$ baixa.

Partindo da análise da amostra deste estudo, foram realizadas análises descritivas referentes ao estilo parental, estilo atribucional e bem-estar psicológico, as quais são explicitadas abaixo.

\section{Estilo parental dos participantes}

Com relação ao estilo parental vivenciado pelos participantes, evidencia-se que a maioria, $60,7 \%$ refere perceber seus pais como autorizantes, enquanto que $24,5 \%$ como autoritários e 14,8 como permissivos.

\section{Estilo atribucional dos participantes}

No que diz respeito à dimensão internalidade/externalidade, dentre as repostas obtidas, $60,2 \%$ dos sujeitos tendem a perceber que os eventos são causados devido a eles próprios (internalidade).

Já no que se refere à dimensão estabilidade/ instabilidade, um pouco mais da metade dos jovens, $57,3 \%$, afirmam acreditar que a atribuição causal para o evento não irá mais afetá-los no futuro (instabilidade).

Concernente à dimensão globalidade/especificidade, 46,1\% acreditam que a atribuição causal da situação afeta outras áreas da vida (globalidade), já 37,5\% pensam que afeta somente a situação em si (especificidade).

\section{Bem-estar psicológico dos participantes}

Com relação ao bem-estar psicológico, $52 \%$ dos respondentes afirmam perceber a presença de elevado índice de bem-estar psicológico, enquanto que $32,2 \%$ disseram ser o habitual, e $4 \%$ referiram a percepção de baixo índice de bemestar psicológico.

Dentre os resultados, destacam-se como mais proeminentes: estilo parental autorizante, estilo atribucional interno, estável e global, assim como elevado índice de bem-estar psicológico.

Desenvolveram-se análises correlacionais com o intuito de interpretar a relação existente entre as variáveis do estudo ${ }^{43}$. As correlações foram significativas, porém os valores obtidos na análise foram relativamente baixos.

Foi identificada a existência de correlação negativa significativa $(r=-0,191$ e $\mathrm{p}<0,05)$ entre estilo parental autorizante e bem-estar psicológico, sendo que ao maior estilo parental autorizante corresponde um maior nível de bem-estar. Com relação ao estilo parental autoritário e o bem-estar, notou-se que há correlação positiva significativa $(\mathrm{r}=0,151 \mathrm{e} \mathrm{p}<0,01)$, ao maior estilo parental autoritário corresponde um menor nível de bem-estar (Tabela 1).

No que se refere aos estilos atribucionais e ao bem-estar psicológico, percebeu-se a existência de correlação positiva significativa $(r=0,318$ e $\mathrm{p}<0,01)$ entre bem-estar e dimensão globalidade/especificidade. Quanto maior o nível de globalidade, menor é o nível de bem-estar psicológico. Com relação à dimensão estabilidade/instabilidade e bem-estar, foi identificada correlação positiva significativa $(\mathrm{r}=0,291 \mathrm{e}$ $\mathrm{p}<0,01$, na medida em que à maior estabilidade corresponde o menor nível de bem-estar psicológico (Tabela 1).

$\mathrm{Na}$ Tabela 2, referente aos estilos parentais e estilos atribucionais, foi possível evidenciar correlação positiva significativa $(r=0,116$ e $\mathrm{p}<0,05$ ) entre estilo parental autoritário e dimensão instabilidade/estabilidade do estilo atribu- 
cional, ou seja, a maior intensidade do estilo autoritário corresponde à maior percepção de estabilidade no estilo atribucional. Já com relação ao estilo parental autorizante e a dimensão instabilidade/estabilidade, quanto mais autorizantes forem as estratégias educacionais, mais instável é o estilo atribucional $(\mathrm{r}=-0,122$ e $\mathrm{p}<0,05)$. Correlação negativa significativa, também, foi evidenciada entre o estilo parental autorizante e a dimensão especificidade/globalidade do estilo atribucional $(\mathrm{r}=0,137$ e $\mathrm{p}<0,05)$ : aos maiores níveis de estilo parental autorizante corresponde a dimensão especificidade do estilo atribucional.

Utilizou-se a análise de regressão a fim de identificar a predição de valores existente de uma variável do estudo em função de outra ${ }^{43}$. São descritas a seguir as análises de acordo com as variáveis.

\section{Estilos Parentais e Estilos Atribucionais}

Conforme apresentado na Tabela 3, identifica-se que o estilo parental autoritário prediz a dimensão internalidade do estilo atribucional, havendo nível de significância de 0,001 e explicando 3,4\% da variância. Os estilos parentais permissivo e autorizante, juntamente com as dimensões dos estilos atribucionais especificidade/globalidade e instabilidade/estabilidade foram excluídos da análise por não apresentarem significância estatística.

Tabela 1. Estilo Parental, Estilo Atribucional e Bem-Estar Psicológico.

\begin{tabular}{|c|c|c|c|c|c|c|}
\hline & $\begin{array}{l}\text { Estilo Parental } \\
\text { Permissivo }\end{array}$ & $\begin{array}{c}\text { Estilo Parental } \\
\text { Autoritário }\end{array}$ & $\begin{array}{c}\text { Estilo Parental } \\
\text { Autorizante }\end{array}$ & $\begin{array}{c}\text { Dimensão } \\
\text { internalidade/ } \\
\text { externalidade do } \\
\text { estilo atribucional }\end{array}$ & $\begin{array}{c}\text { Dimensão } \\
\text { instabilidade/ } \\
\text { estabilidade do } \\
\text { estilo atribucional }\end{array}$ & $\begin{array}{l}\text { Dimensão } \\
\text { especificidade/ } \\
\text { globalidade. do } \\
\text { estilo atribucional }\end{array}$ \\
\hline $\begin{array}{l}\text { Bem-Estar } \\
\text { Psicológico }\end{array}$ & 0,071 & $0,151^{*}$ & $-0,191 * *$ & 0,042 & $0,291 * *$ & $0,318^{* *}$ \\
\hline
\end{tabular}

$* p<=0,01 . * * p<=0,05$

Tabela 2. Estilo Parental e Atribucional

\begin{tabular}{lccc}
\hline & $\begin{array}{c}\text { Dimensão internalidade/ } \\
\text { externalidade do estilo } \\
\text { atribucional }\end{array}$ & $\begin{array}{c}\text { Dimensão instabilidade/ } \\
\text { estabilidade do estilo } \\
\text { atribucional }\end{array}$ & $\begin{array}{c}\text { Dimensão especificidade/ } \\
\text { globalidade. do estilo } \\
\text { atribucional }\end{array}$ \\
\hline Estilo Parental Permissivo & 0,046 & 0,053 & 0,071 \\
\hline Estilo Parental Autoritário & $-0,014$ & $0,116^{*}$ & 0,027 \\
\hline Estilo Parental Autorizante & $-0,087$ & $-0,122^{*}$ & $-0,137^{*}$ \\
\hline
\end{tabular}

$* p<=0,01 . * * \quad p<=0,05$

Tabela 3. Preditor da dimensão internalidade do Estilo atribucional e Estilos Parentais

\begin{tabular}{|c|c|c|c|c|c|}
\hline \multicolumn{6}{|c|}{ Modelo Sumário } \\
\hline $\mathrm{R}$ & & $\mathrm{R}^{2}$ & & $\mathrm{R}^{2}$ ajustado & Erro Padrão do estimado \\
\hline 0,183 & & 0,034 & & 0,030 & 0,30056 \\
\hline \multicolumn{6}{|c|}{ Coeficientes Estatísticos } \\
\hline & B & & Beta & $\mathrm{t}$ & $\mathrm{p}$ \\
\hline (Constante) & 2,042 & & & 104,813 & $<0,0001$ \\
\hline E.P. Autoritário & 0,134 & & 0,183 & 3,253 & $<0,001$ \\
\hline
\end{tabular}


Tabela 4. Preditor do Bem-Estar Psicológico e Estilos Parentais

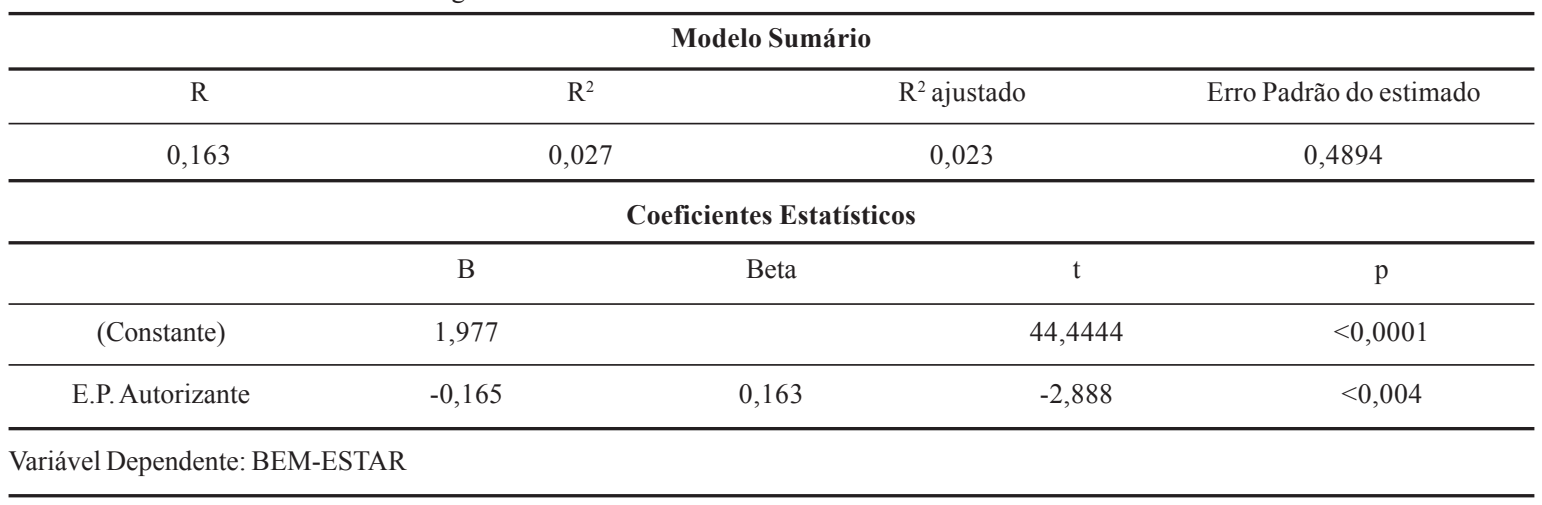

Tabela 5. Preditor de Bem-Estar Psicológico e Estilos Atribucionais

\begin{tabular}{ccccc}
\hline \multicolumn{5}{c}{ Modelo Sumário } \\
\hline $\mathrm{R}$ & \multicolumn{2}{c}{$\mathrm{R}^{2}$} & $\mathrm{R}^{2}$ ajustado & Erro Padrão do estimado \\
\hline 0,345 & & 0,119 & 0,113 & 0,4711 \\
\hline & & Coeficientes Estatísticos & $\mathrm{p}$ \\
\hline & $\mathrm{B}$ & $\mathrm{B}$ eta & $\mathrm{t}$ & $<0,0001$ \\
\hline (Constante) & 0,944 & & 5,930 & $<0,002$ \\
\hline ELOBALI & 0,129 & 0,228 & 3,177 & $<0,033$ \\
\hline
\end{tabular}

Variável Dependente: BEM-ESTAR

Cabe salientar que, na análise correlacional desenvolvida anteriormente, não foram encontrados resultados significativos com relação ao estilo parental autoritário e dimensão internalidade da atribuição.

\section{Bem-Estar Psicológico (GHQ) e Estilos Parentais}

O estilo parental autorizante prediz bemestar psicológico, sendo a variância de $2,7 \%$, e o nível de significância de 0,004 . Os demais estilos parentais (autoritário e permissivo) foram excluídos da análise, por não apresentarem significância estatística para análise de regressão (Tabela 4).

Estes achados vão ao encontro das análises correlacionais com relação a estas variáveis, tendo em vista que a maior intensidade do estilo parental autorizante corresponde a elevados níveis de bemestar psicológico (Tabela 1).

\section{Bem-Estar Psicológico (GHQ) e Estilos Atribucionais}

A globalidade e a estabilidade nos estilos atribucionais predizem níveis mais baixos de bemestar psicológico, explicando $11,9 \%$ da variância. O nível de significância para o estilo atribucional global foi de 0,002 e, para o estilo atribucional estável, de 0,033 (Tabela 5). Já a dimensão externalidade/internalidade foi excluída da análise de regressão por apresentar significância insuficiente para tal.

Estes achados corroboram com as correlações encontradas entre estilos atribucionais e bemestar psicológico, pois foi percebido que quanto 
mais intensas forem a globalidade e a estabilidade da atribuição, menores serão os níveis de bemestar (Tabela 1).

\section{DISCUSSÃO}

Mais da metade dos participantes da pesquisa $(60,7 \%)$ percebe o estilo parental de seus pais como autorizante. $\mathrm{Na}$ adultez jovem, há o resgate do olhar mais contextualizado da realidade familiar pois a saída da adolescência possibilita que os aspectos tumultuados e confusos vivenciados anteriormente estejam mais claros. Há um retorno aos pais e familiares com o intuito de reconstrução de suas imagens ${ }^{15}$. Portanto, o fato de a maioria dos participantes relacionarem seus pais com o estilo parental ideal - o autorizante pode ser atribuído a esse olhar que visa a um resgate de pontos saudáveis da família original.

No que se refere à percepção dos estilos atribucionais, a maior parte afirmou ser mais interno, estável e global. A internalidade, ao mesmo tempo que possibilita a construção de locus de controle sobre a situação, pode afetar negativamente a auto-estima ${ }^{20}$. A estabilidade, por sua vez, diz respeito à persistência ao longo do tempo; e a globalidade, à ampla influência sobre outros pontos da vida. Tais achados podem estar associados ao período universitário vivenciado pelos participantes, pois se sabe que esse é um momento um tanto intenso, quando ainda não há garantias com relação ao futuro, aspecto que pode influenciar a percepção das atribuições de causalidade frente a eventos negativos.

À maior intensidade do estilo parental autorizante corresponde um maior nível de bemestar. É referenciado na literatura o equilíbrio de poder, a sinergia entre o controle e o afeto, e a abertura ao diálogo como práticas existentes na estratégia autorizante; aspectos que irão influir de forma expressiva na saúde psicológica do sujeito. A criança sente-se amada e segura, ao mesmo tempo em que há espaço para a busca de autonomia. Sem dúvida, esses pontos possibilitam a construção de uma identidade mais segura, uma auto-estima mais positiva, características que repercutem diretamente no bem-estar psíquico ${ }^{1-3}$.
No que concerne ao estilo parental autoritário, quanto maior foi a veemência desse estilo, menor foi o nível de bem-estar psicológico. Sabese que, no estilo autoritário, não há congruência entre controle, afeto e poder. Nota-se que a percepção dos jovens condiz com a literatura sobre o estilo parental autoritário, já que a maioria salienta os malefícios para o desenvolvimento psicológico e social do ser humano ${ }^{2}$.

No que se refere aos estilos atribucionais, percebeu-se que quanto maior o nível da globalidade e da estabilidade na atribuição, menores os níveis do bem-estar psicológico. A análise de regressão vai ao encontro da análise correlacional pois, quando há estabilidade e globalidade nas atribuições causais, há predição de piores níveis de bem-estar psicológico. Seligman ${ }^{21-22}$ e Cutrona ${ }^{44}$ descrevem as dimensões internalidade, estabilidade e globalidade das atribuições como associadas aos piores níveis de saúde mental. A bibliografia empírica aponta a presença das dimensões globalidade e estabilidade associada aos quadros depressivos $^{25-26}$. Se um evento negativo ocorre, e a pessoa passa a acreditar que este afetará outras inúmeras áreas da sua vida, há uma tendência lógica a intensificar o efeito negativo de tal evento.

Ainda apoiando esses resultados, no estudo de Chiara $^{30}$ sobre a relação existente entre os estilos atribucionais e o bem-estar, foi identificado que estilos atribucionais externos, instáveis e específicos servem como protetores no desenvolvimento de sintomas e episódios depressivos. Isso ocorreria devido ao fato de a pessoa não "globalizar" para demais eventos (específico), não interpretar o ocorrido como persistente ao longo do tempo (instável) e, tampouco, enxergar a si como o único participante (externo).

No que tange aos estilos parentais e estilos atribucionais, primeiramente foi possível evidenciar que a maior intensidade do estilo autoritário relaciona-se à maior estabilidade no estilo atribucional. Ambos (o estilo autoritário e a atribuição estável) estão mais relacionados com comportamentos negativos. Peterson e Seligman ${ }^{20}$ afirmam haver relação direta entre a estabilidade da atribuição causal e baixa auto-estima, depressão e desesperança. Já com relação ao estilo parental autoritário, Lamborn e cols. ${ }^{10}$ salientam 
que, quando se nota a referência dos pais como autoritários, há a tendência à conformação dos padrões sociais e presença de auto-conceitos mais negativos. Os jovens que vivenciam o estilo autoritário possivelmente não têm espaço para a construção de uma autonomia e auto-conceito sólidos, aspectos que trazem insegurança frente às situações negativas.

Os jovens participantes estão vivenciando um período de transição para a vida adulta, em um contexto social extremamente paradoxal, já que por um lado lhes é exigido uma postura de adultos, mas a dependência financeira faz com que retardem a saída de casa e a construção de uma verdadeira autonomia. Essa vivência paradoxal traz inseguranças naturais, as quais poderão ser mais intensas quando houver história de autoridade parental na infância.

No que diz respeito ao estilo parental autorizante, quanto mais autorizantes forem as estratégias educacionais, mais instável e específico é o estilo atribucional. Foi reportado em estudos prévios que o estilo autorizante possibilita um desenvolvimento mais saudável ${ }^{9}$. Além isso, Peterson e Seligman ${ }^{20}$ salientam que quanto maior a instabilidade e especificidade na atribuição, maiores as possibilidades de saúde psíquica. Outro ponto relevante é que, quando os jovens reportam que houve espaço para autonomia e diálogo na relação com seus pais, se nota a predição de maiores índices de bem-estar

Percebe-se que os jovens que identificam seus pais como autorizantes tendem a desenvolver maiores habilidades frente às situações difíceis, assim como melhores níveis de saúde psíquica ${ }^{2,7}$. Assim sendo, é natural esperar que venham a desenvolver estilos atribucionais mais saudáveis. Conseguir olhar para o passado infantil considerando os aspectos saudáveis ou, ainda, vislumbrar os pais cuidadores de forma positiva possivelmente possibilite, por si só, o enfrentamento de situações estressantes de forma mais adequada e, conseqüentemente, ter maior satisfação pessoal.

Pouco mais da metade dos respondentes apresentou elevados níveis de bem-estar psicológico, já 32,2\% disseram que percebem seu bem-estar como o de costume, e $4 \%$ referiram a percepção de baixo índice de bem-estar psicoló- gico. Devemos considerar também que se está diante de uma população de classe média e média alta, a qual vivencia uma realidade com recursos e possibilidades amplas tendo em vista nossa realidade contextual. Esses são pontos que podem trazer maior tranqüilidade e segurança. Ao mesmo tempo, é importante salientar que, na avaliação do bem-estar, há o fenômeno da desejabilidade social, aspecto que pode estar presente de forma intensa nessa fase desenvolvimental, distanciando o acesso ao que realmente acontece, pois se sabe da existência de diferenças entre o que uma pessoa realmente sente e o que ela gostaria de sentir.

Ao mesmo tempo, quando se demonstra que o estilo parental autoritário prediz a internalidade da atribuição, comprova-se que vivências prévias fundamentadas na autoridade - ausência de diálogo e desequilíbrio entre o afeto e o controle originam maiores justificativas internas para os acontecimentos negativas ${ }^{10,20}$. São jovens que tendem a se culpar de forma intensa; logo, a gratificação pessoal é difícil, e o autoconceito tende a ser mais precário.

Cabe salientar que as correlações oriundas das análises apresentaram coeficientes relativamente baixos, porém com significância. Podese justificar isto devido ao fato do comportamento humano ser multifatorial.

\section{CONSIDERAÇÕES GERAIS}

A maior parte dos resultados vai ao encontro da literatura vigente, assim como estão relacionados a perspectivas saudáveis, principalmente no que se refere à percepção dos estilos parentais e do bem-estar psicológico. É importante considerar que a população participante se encontra em uma fase desenvolvimental particular. Se, por um lado, vivencia a oportunidade de olhar para os pais de forma mais madura, resgatando seus pontos positivos e aceitando as suas dificuldades; por outro, oscila entre o mundo amadurecido e adolescente, tendo experiências adultas e, ao mesmo tempo, sendo dependente dos pais, aspecto fortemente influenciado pela questão contextual atual. Esses pontos podem ser fortes agentes promotores dos resultados encontrados neste 
estudo, já que os jovens enxergam seus pais como ótimos educadores e orientadores, mas ainda apresentavam algumas características de insegurança frente às situações difíceis, aspecto percebido na análise das respostas com relação aos estilos atribucionais internos, estáveis e globais.

O presente trabalho reflete a percepção de uma parcela da população, ponto que salienta a relevância de novos estudos em amostras diversificadas. Ao mesmo tempo, os achados ressaltam a importância do papel que a família exerce em nossa sociedade. Espera-se que estes suscitem reflexões, assim como motivem para uma práxis que vislumbre vivências mais justas e saudáveis. Pesquisar e intervir partindo de contextos educacionais suscita novas percepções acerca de possibilidades de desenvolvimento e amadurecimento de adultos mais saudáveis, o que resulta em uma sociedade mais equilibrada.

Sugere-se a elaboração de estudos que possibilitem entender de que forma os estilos parentais, assim como as atribuições causais, são elaborados e vivenciados na prática. Além disso, incluir a percepção dos pais com relação aos seus estilos parentais seria um excelente fator para ampliar o entendimento do fenômeno.

\begin{abstract}
The family has some essential tasks concerning the person's development. Therefore, the present study searched for correlations between educational strategies, attributional styles and psychological wellbeing among young adults attending universities. Correlation and multiple regression analyses were conducted. Results showed that the authoritative parental style correlates with high wellbeing scores. On the other hand, the more intense authoritarian parental styles were related to higher levels of stability in causal attribution. Concerning attributional styles, it was possible to note that the dimensions globality and stability corresponded to lower psychological wellbeing levels. These outcomes emphasize the importance of the effects of parental styles and attributional styles on the psychological wellbeing, focusing on future psychoeducational actions.
\end{abstract}

Key words: Parental styles. Attributional styles. Psychological wellbeing. Young adults.

\section{REFERÊNCIAS}

1. Baumrind D. Parental control and parental love. Children 1985; 12(6): 230-4.

2. Baumrind D. Parental Disciplinary Patterns and Social Competence in Children. Youth \& Society 1978;,9(1): 239-75.

3. Baumrind D. New directions in socialization research. American Psychologist 1980; 9: 293-306.

4. Baumrind D. The discipline controversy revisited. Family Relations 1996; 5: 405-13.

5. Cheng H, Furnham A. Perceived parental behavior, self-esteem and happiness. Soc Psychiatry Epidemiol 2000; 35: 463-70.

6. Pinderhughes EE, Dodge KA, Bates JE, Pettit GS, Zelli A. Discipline responses: influences of parent's socioeconomic status, ethnicity, beliefs about parenting, stress, and cognitiveemotional process. Journal of Family Psychology 2000; 14 (3): 380-400.

7. Henderson DO. Understanding parenting style as a preventive construct for adolescent males. Dissertation Abstracts International 2001; 62(3): 120.
8. Miller JM, DiIorio C, Dudley W. Parenting style and adolescent's reaction to conflict: is there a relationship? Journal of Adolescent Health 2002; 31: 463-8.

9. Musito G, Cava MJ. La familia y la educación. Barcelona: Octaedro; 2001.

10. Lamborn SD, Mounts N, Steinberg L, Dornbusch SM. Patterns of competence and adjustment of adolescents from authoritativem, authoritarian, indulgent, and neglectful families. Child Development 1991; 62: 1049-65.

11. Bronfenbrenner U. A ecologia do desenvolvimento humano: experimentos naturais e planejados. Porto Alegre: Artes Médicas; 1996.

12. Buri JR, Louiselle PA, Misukanis TM, Mueller RA. Effects of parental authoritativeness on self-esteem. Personality and Social Psychology Bulletin 1988; 14(2): 271-82.

13. Petito F, Cummins RA. Quality of life in adolescence: the role of perceived control, parenting style and social support. Behavior Change 2000; 17(3): 196-207. 
14. Sarriera JC. (1993). Aspectos psicosociales del desempleo juvenil: un análisis desde el fracaso escolar para la intervención preventiva [tese]. Madrid: Facultad de Psicología. Universidad Autonomía de Madrid; 1993.

15. Carter B, McGoldrick M. The family life circle. In: Walsh F. Normal family process. growing diversity and complexity. Nova York: The Gilford Press; 2003. p. 375-98.

16. Morales JF, organizador. Psicología Social. Madrid: McGrawHill; 1999.

17. Kelley HH. The process of causal attribution, American Psychologist 1973; 28: 107-28.

18. Weiner B. A cognitive (attributional)emotional-action model of motivated behavior: An analysis of judgments of help-giving. Journal of Personality and Social Psychology 1980; 39: 186-200.

19. Weiner B. An attributional achievement motivation and emotion. Psychological Rewiew 1985; 92(4): 548-73.

20. Peterson C, Seligman MEP. Causal explanations as a risk factors for depression: theory and evidence. Psychological Review 1984; 91(3): 347-74.

21. Seligman MEP. Learned helplessness. Annual Review of Medicine 1972; 23: 407-12.

22. Seligman MEP. Helplessness: on depression, development and death. San Francisco: Freeman; 1975.

23. Abramson LY, Seligman MEP, Teasdale JD. Learned helplessness in humans: critique and reformulation. Journal of Abnormal Psychology 1978; 87: 59-74.

24. Seligman MEP, Castellon C, Cacciola J, Schulman P. Explanatory style change during cognitive therapy for unipolar depression. Journal of Abnormal Psychology 1988; 97: 13-8.

25. Ingram RE, Atkinson JH, Slater MA, Saccuzzo DP. Negative and positive cognition in depressed and nondepressed chronic-pain patients. Health Psychology 1990; 9: 300-14.

26. Gillham J, Reivich K, Jaycox L, Seligman MEP. Prevention of depressive symptoms in school children: two year follow up. Psychological Science 1995; 6(6), 343-51.

27. Haugen R, Lund T. Self-concept, attributional style and depression. Educational Psychology 2002; 22(3): 305-16.

28. Lam CY. Verbal ability, social skills, attributional style, negative events, and depressive symptoms in college students: a preliminary examination of the unified diathesis-stress theory of depression. Dissertation Abstracts International 2002; 62(12b): 5968.

29. Rigby BT. The joint influence of personality and causal attributions on adolescent's life satisfaction. Dissertation Abstracts International 2003; 63(7b): 3506.

30. Chiara AM. Multidimensional optimism and well-being: A prospective study of multiple concepts of optimism as protective factors following high stress. Dissertation Abstracts International - The Science and Engineering 2002; 63(1b): 517.

31. Seligman MEP, Nolen-Hoeksema S, Thornton N, Thornton KM. Explanatory style as a mechanism of disappointing athletic performance. Psychological Science 1990; 1: 143-6.

32. Glasgow KL, Dornbusch LT, Steinberg L, Ritter P. Parenting styles, adolescent's attributions, and educational outcomes in nine heterogeneous High Schools, Child Development 1997: 68(3): 507-29.

33. Martinez R., Sewell KW. Explanatory style in college students: gender differences and disability status. College Student Journal, 34(1): 72-9; 2000.

34. Monestere CM. The relationship of identity status, perceived parental explanatory style, and sex adult attributional style and attributions for failure. Digital Dissertation. Michigan State University; 2002.

35. Nolen-Hoeksema S, Girgus JS, Seligman MEP. Predictors and consequences of childhood depressive symptoms: a 5yearlongitudinal study. Journal of Abnormal Psychology 1992; 101: 405-22.

36. Burns M O, Seligman MEP. Explanatory style across the life span: evidence for stability over 52 years. Journal of Personality and Social Psychology 1989; 56: 471-7.

37. Peterson C, Semmel A, von Baeyer C, Abramson LY, Metalsky GI, Seligman MEP. The Attributional Style Questionnaire. CognitiveTherapy and Research 1982; 6: 287 99.

38. Schwartz JAJ, Kaslow NJ, Seeley J, Lewinsohn P. Psychological, cognitive, and interpersonal correlates of attributional change in adolescents. Journal of Clinical Child Psychology 2000; 29(2), 188-98.

39. Peterson C, Villanova P. An expanded Attributional Style Questionnaire. Journal of Abnormal Psychology 1988; 97(1): 87-9. 
40. Goldberg D. The detection of psychiatric illness by questionnaire. London, Oxford: University Press; 1972.

41. Sarriera JC, Schwarcs C, Câmara SG. Bemestar Psicológico: Análise Fatorial da Escala de Goldberg (GHQ-12), numa amostra de jovens. Psicologia: Reflexão e Crítica 1996; 9(2): 323-36.

42. Buri JR. Parental Authority Questionnaire.
Journal of Personality Assessment 1991; 57(1): 110-9.

43. Bisquerra R, Sarriera JC, Martínex,F. Introdução à estatística - Enfoque informático com o pacote estatístico SPSS. Porto Alegre: Artmed; 2004.

44. Cutrona CE. Causal attributions and perinatal depression. Journal of Abnormal Psychology 1983; 92: 161-72.

Recebido em: 08/05/2005

Modificado em: 26/03/2006

Aprovado em: 10/09/2006 